International Journal of Child, Youth and Family Studies (2015) 6(4.1): 746-770

\title{
IMMIGRANT AND REFUGEE YOUTH SETTLEMENT EXPERIENCES: “A NEW KIND OF WAR”
}

\author{
Marian J. Rossiter, Sarvenaz Hatami, \\ Daniel Ripley, and Katherine R. Rossiter
}

\begin{abstract}
The settlement and adaptation of immigrant and refugee youth in receiving countries is a long-term process with many challenges. In this study, we explored factors that influenced the settlement experiences of 14 immigrant and refugee youth who arrived in Canada as adolescents. The interviewees ( 9 male, 5 female) ranged in age from 19 to 32 years and represented 10 source countries. Analyses of the semi-structured interview transcripts revealed that their settlement and adaptation were negatively influenced by pre-migration experiences; difficult socioeconomic circumstances in Canada; lack of knowledge of Canadian laws and legal sanctions; challenging educational experiences; racism and discrimination; and cultural identity issues. However, several factors exerted a positive influence on participants' settlement experiences or served to mitigate the negative influences in their lives: in particular, strong support networks and involvement in prosocial community programs as participants and/or leaders. We make recommendations for facilitating the integration process in school settings and in the wider community.
\end{abstract}

Keywords: immigrant youth; refugee youth; settlement; integration; crime

Acknowledgements: We would like to express our appreciation to the immigrant and refugee youth who participated in this study; to our community partners and Correctional Services, Alberta Solicitor General and Public Security for their support; and to research assistants L. Sallis and L. Nickel. We are very grateful to the Prairie Metropolis Centre and the Metropolis Project for funding this research, and to two anonymous reviewers for their helpful comments.

Marian J. Rossiter (the corresponding author) is an Associate Professor in the Teaching English as a Second Language (TESL) program in the Department of Educational Psychology, 6-102 Education North, University of Alberta, Edmonton, AB, Canada T6G 2G5. E-mail: marian.rossiter@ualberta.ca

Sarvenaz Hatami has a PhD in Teaching English as a Second Language from the Department of Educational Psychology at the University of Alberta, Canada. E-mail: sarvenaz.hatami@ualberta.ca

Dan Ripley, MEd, is a LINC instructor and online classroom developer at MOSAIC English Language Centre, 205-123 East 15th Street, North Vancouver, BC V7L 2P7. Email:

dripley@mosaicbc.com

Katherine R. Rossiter is an Adjunct Professor in the School of Criminology at Simon Fraser University, 8888 University Drive, Burnaby, V5A 1S6. Email: rossiter@sfu.ca 
Canada is a nation of increasing diversity: its 6.8 million immigrants represent approximately 200 countries of origin and native languages (Statistics Canada, 2011). In recent years, it has welcomed 200,000 to 250,000 immigrants annually, approximately $0.8 \%$ of its population (Ferrer, Picot, \& Riddell, 2014). Between 2008 and 2012, youth aged 15 to 24 years accounted for an average of $17 \%$ of that number (Citizenship and Immigration Canada, 2012). By 2016, the Canadian Council on Social Development (2006) has estimated, immigrant youth and Canadian-born children of immigrant families will represent $25 \%$ of the country's population under the age of 18 . The extent to which newcomer youth integrate into society will have a significant impact on the roles that they play in it. As a result, "it becomes imperative for researchers, service providers, and social policymakers to investigate the multiple challenges and barriers that newcomer youth face as they navigate through their adjustment and settlement processes” (Chuang \& Canadian Immigrant Settlement Sector Alliance [CISSA], 2010, p. 1).

Immigrants who arrive as adolescents face unique educational, cultural, linguistic, economic, and psychosocial challenges that may negatively affect their settlement, adaptation, and integration experiences (Ngo \& Schleifer, 2005). As Berger (2008) notes, immigrant adolescents also face challenges associated with the transition from childhood to adulthood. Despite difficult pre-migration or migration experiences, however, many youth exhibit resilience, defined by Ungar (2012) as "a set of behaviours over time that reflect the interactions between individuals and their environments, in particular the opportunities for personal growth that are available and accessible” (p. 14). Several individual and environmental factors that promote resilience in immigrant children and youth have been reported in the literature, including individual traits (e.g., adaptability, self-esteem, optimism); parental psychological health; family integrity and support; availability of schooling; the school environment; and peer and community support (Este \& Ngo, 2011; Montgomery, 2010; Rothe, Pumariega, \& Sabagh, 2011).

For many immigrant youth, however, negative experiences in their home countries have a continuing influence on their adaptation to a new culture. For example, refugees may have witnessed or experienced war, violence, persecution, rape, and torture; and they may have suffered malnutrition, infectious disease, and brutality in refugee camps. The effects of these experiences can include anxiety, anger, flashbacks, disruption of sleep patterns, symptoms of Post-Traumatic Stress Disorder (PTSD), learning disabilities, and fear of authority (e.g., Ellis, MacDonald, Lincoln, \& Cabral, 2008; Kanu, 2008; Magro, 2009; McBrien, 2005; Ngo, 2010; Ngo \& Schleifer, 2005; Seat, 2003; Wilson, Murtaza, \& Shakya, 2010). Resettlement itself exerts additional economic, educational, and psychosocial stresses on newcomer youth (Chuang \& CISSA, 2009, 2010; Lustig et al., 2004; Ngo \& Schleifer, 2005; Seat, 2003; Shakya, Khanlou, \& Gonsalves, 2010), which can exacerbate the impact of pre-migration experiences (e.g., Ellis et al., 2008; Kanu, 2008; Seat, 2003; Wilson et al., 2010). Kanu (2008), for example, reported a case in which a high school fire drill triggered a heightened stress response in a traumatized Sudanese refugee, leading to hospitalization (p. 932).

Economic issues also negatively affect many newcomer youth and their families. Lowincome rates rose dramatically among immigrants to Canada between 1980 and 2005 (Picot, Lu, \& Hou, 2009), and the income gap between Canadian-born and new immigrant workers has 
continued to increase (Frank, Phythian, Walters, \& Anisef, 2013). Child poverty rates in Canada in 2006 were highest in the immigrant (41\%) and recent immigrant (48\%) groups (Campaign 2000, 2012) due to "the decline in the economic fortunes of successive cohorts of newly arriving immigrants” (Reitz, 2014, p. 111). According to Ferrer et al. (2014), the current poverty rate of recent immigrants is nearly double that recorded in the early 1980s and 2.7 times greater than that of the general population (p. 850). Many newcomer families have great difficulty early on providing adequate nutrition, warm clothing, secure and appropriate housing in safe neighbourhoods, and other necessities for the healthy development of their children. Parents without English or French language proficiency, employment skills, foreign credentials, or Canadian work experience may struggle to achieve economic stability and may be obliged to work at multiple entry-level jobs. For single parents, particularly mothers, providing sufficient income to meet their families' daily requirements can be especially challenging. Poverty may also expose youth to social problems in low-income neighbourhoods (e.g., Kanu, 2008; Kazemipur \& Halli, 2000; Ngo, 2010; Ngo, Rossiter, \& Stewart, 2013; Rossiter \& Rossiter, 2009) and create stress in families (e.g., Kilbride \& Anisef, 2001; Li, 2010; Shakya et al., 2010).

These experiences are shaped by broader structural factors. Racialized immigrants experience social and economic exclusion and discrimination (Block \& Galabuzi, 2011; Galabuzi, 2006; Shields, Kelly, Park, Prier, \& Fang, 2011). Block and Galabuzi (2011) provide data showing that racialized male newcomers earn $68.7 \%$ of the income of non-racialized male immigrants, and this continues into the second generation. Galabuzi (2006) states that "despite higher levels of educational attainment, disproportionate numbers of racialized workers, confined to precarious forms of work in certain sectors of the economy, cannot utilize their skills and are condemned to low-status occupations and low-wage jobs” (p. 234). Employment for these workers may be contract, temporary, part-time, or piecework, with little or no job security or benefits.

To supplement the family income or to support themselves, youth may find full- or parttime employment while attending school: Wilkinson (2008) found that many employed immigrant and refugee students worked in excess of 30 hours a week. Employment offers several advantages: for example, in addition to helping to improve their economic circumstances or those of their families, employed youth gain the opportunity to improve their linguistic and pragmatic skills, as well as Canadian work experience and familiarity with Canadian culture. However, there are also disadvantages to employment, particularly if youth are both working and attending school. Kanu (2008) reported that the majority of the African refugee high school students from war-torn countries in her study were working full-time to support themselves. Some were also supporting family back home or repaying refugee transportation loans, which cover the cost of refugees' overseas medical examinations and transportation to Canada and may total \$10,000 for parents and minors (Canadian Council for Refugees, n.d.). In Kanu’s (2008) study, teachers in the participants' schools perceived a direct relationship between refugee students’ involvement in full-time employment and their low academic success.

Furthermore, for some newcomer youth, "low-end jobs are long term and an example of significant downward trajectories in their careers” (Lauer, Wilkinson, Yan, Sin, \& Tsang, 2012, p. 8). Some refugee families have been reported to support gang membership or criminal activity to generate income and facilitate the repayment of Canadian government interest-laden 
International Journal of Child, Youth and Family Studies (2015) 6(4.1): 746-770

transportation loans (Ngo et al., 2013; Rossiter \& Rossiter, 2009). Magro (2009) noted the challenge that youth in her study faced in balancing work and school responsibilities and assisting family back home; in the participants' experience, despite the desire and pressure to succeed, the supports and resources required to do so were not always available.

Parents often experience worries and frustrations regarding other aspects of settlement that affect them personally, such as language barriers, changes in status and personal identity, and their relationships within the family and mainstream society (Seat, 2003). When youth adapt to the receiving society and its cultural values (e.g., gender roles, fashion, curfews, and dating) more quickly or easily than their parents, intergenerational conflict may arise (Anisef, Kilbride, \& Khattar, 2003; Chuang \& CISSA, 2009, 2010; Rossiter \& Rossiter, 2009). The deterioration of family and school relationships can result in the unravelling of youths' self-concept, identity, and sense of belonging, and this in turn can lead to other serious problems (Ngo, 2010).

Education is key to successful integration (Anisef et al., 2003; Anisef, Brown, Phythian, Sweet, \& Walters, 2008; Berry, 2008), and immigrant youth have high educational aspirations (e.g., Krahn \& Taylor, 2005; Seat, 2003). Newcomer youth have both extensive and intensive contact with Canadian schools (Wilkinson, 2002), and these institutions have the potential to provide the support and resources necessary to enhance students' sense of self-worth and belonging in the community (e.g., Anderman, 2002; Dei, 2007). Self-esteem and a sense of belonging, in turn, can foster academic success (e.g., Anderman, 2002) and lead to active participation in the community and the development of pluricultural_competence. Baumeister and Leary (1995) assert that belonging is a basic human need and that lack of a sense of belonging leads to negative outcomes. Among those identified in the immigration literature are low academic grades, social rejection, psychological distress (e.g., depression, hopelessness), victimization, and gang membership (e.g., Anderman, 2002; Kia-Keating \& Ellis, 2007; Ngo, 2010; Ngo \& Schleifer, 2005).

Although basic interpersonal communication skills in a second language are typically acquired within two to three years, the cognitive academic language proficiency skills required for success in school take from five to seven years to develop (Cummins, 2000). Youth who enter secondary schools with low second-language proficiency face greater challenges in achieving high school completion. Since the introduction of the Immigrant and Refugee Protection Act in 2002, Canada has selected refugees on the basis of humanitarian need rather than adaptability. As a result, educators are faced with an increasing number of refugee youth with multiple, complex needs and gaps in their formal education. O’Hara and Pritchard (2008) assert that "the provision of English language and subject matter instruction to English learners is one of the most critical challenges confronting teachers and teacher educators today" (p. 43). However, Howard Research and Management Consulting (2006) suggested that K-12 teachers in school systems in the province of Alberta were inadequately prepared to meet the challenges posed by immigrant students in their classes. Only 14\% of the schools surveyed in the 2006 study reported that their English as a second language (ESL)-designated teachers had a Teaching English as a Second Language (TESL) diploma, certificate, or degree.

Alberta studies show immigrant high school dropout rates of between 61\% (Derwing, DeCorby, Ichikawa, \& Jamieson, 1999) and 74\% (Watt \& Roessingh, 1994). More recent immigrant non-completion rates in British Columbia schools of 38\% (Garnett, 2010) and 40\% 
(Toohey \& Derwing, 2008) are lower, but completion rates still leave much room for improvement. Because they have limited literacy and employment skills, immigrant youth who fail to complete high school have difficulty gaining employment and could be at risk of becoming involved in crime and violence, which seem to promise easy access to income and relief from poverty (e.g., Ngo et al., 2013; Kanu, 2008).

Discrimination can exacerbate acculturation challenges and lead to low self-esteem, stress, depression, poor academic performance, school dropout, substance abuse, and behavioural problems (Chuang \& CISSA, 2009, 2010; Kanu, 2009; Oxman-Martinez et al., 2012; Shakya et al., 2010). The bullying and teasing that take place in schools can also lead to the marginalization and isolation of minority youth. Males tend to be victims of bullying and violence, whereas females more frequently suffer teasing or taunting because of their lack of English, immigrant status, or newness to the school (e.g., Anisef et al., 2003). Oxman-Martinez et al. (2012) found that "being a child from an immigrant single-parent family predicts higher perceived discrimination by peers and teachers, greater likelihood of feeling like an outsider at school, and lower academic grades” (p. 385). Research by Berry, Phinney, Sam, and Vedder (2006) has shown that discrimination discourages involvement in the receiving society and contributes to an increased orientation toward newcomers' own ethnocultural groups or ambivalence about their involvement in the new culture, thus hindering cultural integration and the development of a pluricultural_identity.

Participation in prosocial activities plays an important role in the settlement of newcomer youth. In the immigration literature, youth with strong support networks (e.g., friends, family, faith communities) have been found to adapt more easily to their new culture (Anisef et al., 2003; Lamba \& Krahn, 2003). Involvement in supported prosocial extra-curricular activities, particularly with youth outside their own ethnocultural groups, can provide immigrant adolescents with potential role models, as well as valuable social capital and opportunities for integration (e.g., Anisef et al., 2003; Chuang \& CISSA, 2009; Ngo et al., 2013; Rossiter \& Rossiter, 2009; Seat, 2003). Este and Ngo (2011) stated that community-related factors such as immigrant youths' "access to cultural programs and activities ..., involvement with their respective ethnic communities, ... [and] having opportunities to socialize with friends and to play sports” (p. 43) may play important roles in fostering resilience and adaptation.

Schools may provide a wide range of activities in which newcomer youth can become involved (e.g., buddy or mentor programs, clubs, recreational activities); in the larger community, however, there are often numerous barriers to participation. For example, many families are unable to pay fees or assist with fund-raising (e.g., bingos) for programs in their neighbourhoods. One enterprising accommodation in Alberta (LaBoucane-Benson, Hossack, Erickson, \& Grunland, 2009) was initiated by two mothers who organized continuing support for Aboriginal and refugee children in their local soccer league. In a cost-benefit analysis of involvement in soccer programming and crime prevention, the authors estimated that "95 youth could play a season of outdoor soccer for the cost of one youth committing a serious crime as a member of a gang” (p. 8). The opportunity for youth to develop social networks and human capital is key to successful integration.

Another means by which immigrant youth can develop social networks is through volunteering (Ngo et al., 2013; Chuang \& CISSA, 2009, 2010). Ngo et al. (2013) interviewed 
focus groups composed of representatives of ethnocultural communities, service providers, and law enforcement personnel; the groups recommended that newcomer youth become engaged in community volunteer work. They perceived that, as a result of these activities, youth would gain opportunities to develop organizational, language, and leadership skills; demonstrate their abilities; acquire valuable Canadian experience; become empowered; and find increased meaning in their lives. Furthermore, participants asserted, youth who were engaged in out-of-school activities in the community were less likely to become involved in crime. In a study by Dudley (2007), adult ESL newcomers reported that, as a result of their volunteer experiences, they gained a sense of community belonging, as well as insight into Canadian culture (e.g., daily life, customs, habits). Research by Berry and colleagues (2006) has shown that active participation in the receiving culture, combined with the maintenance of immigrants' heritage culture, enhances newcomers' psychological and sociological adaptation. Seat (2003) asserted that "newcomer youth need more help and support in becoming involved in the community, which, along with their families and their schools, is an important pathway for socialization” (p. 193). The linguistic, social, and psychological benefits of volunteering and participating in community activities help to foster youths’ integration into mainstream society.

The immigration literature to date has identified a number of key factors affecting the integration of immigrant and refugee youth: pre-migration experiences, socioeconomic circumstances, family relationships, education, discrimination, and social networks. However, these studies are few in number, and this has given rise to calls for more research related to newcomer children and youth in Canada (e.g., Chuang \& CISSA, 2010; Wideman-Johnston, 2014).

\section{Theoretical and Methodological Framework}

The current study aims to contribute to the existing body of research by examining the perspectives of immigrant youth regarding the factors that they perceived to have had a positive or negative influence on their settlement and integration experiences. Maslow's (1970) hierarchy of needs provides a useful framework for exploring the adaptation of immigrants to their adopted country (Adler, 1977; Nguyen, 1987; Onchwari, Onchwari, \& Keengwe, 2008). Newcomers may initially struggle to satisfy the needs at the base of the hierarchy: physiological needs (e.g., food, sleep) and safety needs (e.g., security, shelter). Before they can reach their potential, however, they must fulfill two additional needs: need for belonging (love of family, friends) and need for esteem (respect, appreciation). The extent to which they are successful in meeting these needs will have a significant impact on their acculturation process.

A qualitative approach was considered to be most appropriate for examining the factors perceived by immigrant youth to influence their settlement and integration experiences. Individual interviews, in particular, gave voice to youth themselves and facilitated the exploration of their adaptation to Canadian society. They also provided a more nuanced understanding of unique positive and negative factors, and how these factors shaped the participants' integration experiences. This offered greater ecological validity; that is, it provided us with first-hand data on the experiences and challenges that this population encounters in their settlement process, as opposed to anecdotal reports from teachers and other stakeholders. 
International Journal of Child, Youth and Family Studies (2015) 6(4.1): 746-770

The following research questions guided our study:

1. What factors do immigrant and refugee youth perceive to have exerted an influence on their settlement and adaptation?

2. What services or programs have interviewees accessed? To what extent have these been perceived as helpful?

\section{Instrument}

A semi-structured interview guide was developed to explore the backgrounds, experiences, and perceptions of youth with respect to their settlement experiences. Interview questions focused on pre-migration experiences; family circumstances; housing and neighbourhoods; school experiences; relationship networks; employment experiences; programs, services, and individuals that may have had an influence on their adaptation; incidence of discrimination and racism; as well as advice to newcomer youth (lessons learned). These factors reflect those identified in earlier studies of the challenges faced by newcomer youth (Anisef et al., 2003; Ngo \& Schleifer, 2005; Rossiter \& Rossiter, 2009). The interviews were conducted and audio-recorded by one of the authors; they ranged from 54 to 108 minutes in length ( $M=75$ minutes).

\section{Recruitment}

Participants in this study were young immigrants or refugees who had arrived in Canada as adolescents and who had sufficient English-language proficiency to enable them to participate in an open-ended interview. With the support of the Government of Alberta Office of the Solicitor General and Public Safety, we initially attempted to recruit youth who had come into conflict with the law. We had little success, due mainly to the reluctance of this population to participate in interviews and of their parents/guardians to grant permission. Therefore, we decided to also recruit, through ethnocultural organizations and social service agencies, youth who were considered leaders or role models in their communities and might be more willing to discuss their experiences. It was anticipated that these participants would provide insight into promising approaches to support immigrant and refugee youth to successfully integrate into Canadian society and to avoid potential negative outcomes, such as involvement in crime and violence.

\section{Data Analysis}

The digital audio files of the interviews were uploaded to a computer and transcribed and verified by research assistants and two of the authors using Express Scribe. We analyzed the data using qualitative data analysis software (NVivo7), coding and categorizing the data broadly, according to areas of inquiry (e.g., pre-migration experiences, family circumstances, school experiences) reflected in the interview instrument. Within each category, the data were analyzed thematically, using an iterative process, to identify shared themes within each category (Denzin \& Lincoln, 2003). Salient themes were selected for inclusion based on their frequency. Multiple readings ensured coding consistency and accurate representation of responses. 
International Journal of Child, Youth and Family Studies (2015) 6(4.1): 746-770

\section{Participants}

A total of 14 youth (9 male, 5 female), 12 of whom were refugees, participated in individual semi-structured interviews. Eleven youth (P1-P11) were recommended by representatives of ethnocultural or social service organizations as leaders or role models in local community groups. The remaining three (P12-P14) had come into conflict with the law and had been referred by staff in a provincial correctional centre, a community corrections office, or a local youth centre. One was incarcerated, one was on parole, and the third was awaiting a second court hearing. The participants ranged in age from 19 to 32 years ( $M=23.7$ years) and had been in Canada for an average of 6.7 years (Range $=1-17$ years; $M d n=5.5$ years). They represented ten source countries: Colombia, Democratic Republic of Congo, Ethiopia, Indonesia, Iraq, Liberia, Mexico, Rwanda, Sierra Leone, and Somalia. Two participants were unaccompanied upon arrival; the others had arrived in Canada with some or all members of their family, but only four had immigrated with both parents. Eight of the interviewees had resided in a country other than their country of birth for an average of 3.5 years (Range: 1-6 years) before immigrating to Canada. Eight participants had some post-secondary education; three had completed high school, two were attending high school, and one had dropped out.

\section{Results and Discussion}

The participants' responses converged to provide the following shared themes within the interviews: (a) pre-migration experiences, (b) socioeconomic circumstances, (c) knowledge of Canadian laws, (d) support networks, (e) educational experiences, (f) racism and discrimination, (g) cultural identity, and (h) involvement in community programs. Several of these themes are captured in one youth's description of initial settlement experiences:

I came from a war-torn country, and coming to Canada for me was like a new kind of war in terms of learning a new language all on your own, in terms of adjusting to the school curriculum all on your own, in terms of being bullied because you couldn't speak English or you didn't have enough money to dress a certain way like everybody else is dressed in school, adjusting to the fact that my parents couldn't find jobs because they couldn't speak English and we just didn't have enough to eat and we didn't have anything to do. (P8)

Because we found no significant differences between the responses of the criminally involved youth and the youth leaders, we have combined them below and noted divergence where it occurred.

\section{Pre-migration Experiences}

In addition to post-arrival stresses, many youth had negative pre-migration experiences, including exposure to violence and war, which affected their daily lives in Canada:

I was young.... You don't really understand it at that time, but now that I'm older, I have flashbacks of the war, and of the things that I witnessed, and so it's becoming harder now for me to adjust to what happened then than it was when I was younger. (P8) 
International Journal of Child, Youth and Family Studies (2015) 6(4.1): 746-770

Explained another, reminiscent of one youth's reaction to fire drills in Kanu’s (2008) study:

When I hear noises, like a loud boom, I react.... Should I run, should I take cover, or you don't know which direction, 'cause in the refugee camp people just start running from some direction and you see someone running, [shouting] "They're shooting, they're coming”. (P5)

Several participants felt that pre-migration experiences made many newcomer youth particularly vulnerable to substance abuse. As one explained:

I know some people that are gang affiliated and that rely on drugs for survival. And these are former child soldiers in their native country, and kids that have been traumatized by war, or have lost their parents through wars or AIDS, or just have had very traumatic experiences. And upon arrival to Canada, I guess they still had that resentment and posttraumatic stress.... So they do abuse drugs on a regular basis.... And yeah, some may have ended up dead or in jail, you know, because of it. (P2)

Another added that pre-migration experiences, exacerbated by post-migration circumstances, may also increase refugee youths’ vulnerability to alcohol and drug abuse:

It's a coping mechanism.... You know, they want to get high ... or get drunk and forget about what's going on at home or ... school.... They've been in refugee camps.... I think once they get back into the real world, they figure out how hard it is for them to start over again and a lot of them ... don't have the strength or the support system to do that. (P8)

Similar effects of pre-migration experiences on refugee youth have been reported in the literature (see, for example, Ellis et al., 2008; Magro, 2009; Ngo, 2010; Ngo et al., 2013; Ngo \& Schleifer, 2005; Rossiter \& Rossiter, 2009; Wilson et al., 2010). The participants in this study confirmed the link between the pre-migration experiences of newcomer refugee youth and their potential for subsequent substance abuse and gang involvement.

\section{Socioeconomic Circumstances}

Financial stress was a concern for most participants and their families. The need to provide an income for the family often meant that English and other employment skills were not acquired, thereby limiting future employment and opportunities for socialization and integration, as in this case: "My [older siblings] were working, paying for their [refugee] transportation loan and also ours. So that was a bit challenging because they missed out on their education and even on their communication skill” (P2). Experiences such as these have given rise to calls for the elimination of refugee transportation loan repayment (e.g., Kanu, 2008; Ngo et al., 2013; Rossiter \& Rossiter, 2009).

The parents of many participants in this study were unemployed or under-employed after arrival in Canada, due to lack of recognition of their foreign credentials. One youth explained:

My dad was an engineer.... And he has a big experience [in our home country], but when he came here, they wouldn't take anything he has. He has to start all over again. Up to date, he hasn't been able to find a job. (P1) 
One youth (P6) explained that although she needed glasses, the family was unable to afford them, despite moving to cheaper accommodation, because winter clothing and other basic necessities were a higher priority. These accounts are representative of circumstances faced by low-income newcomer families (e.g., Picot et al., 2009; Ferrer et al., 2014). Single parents and their families were particularly disadvantaged, as described by this participant:

By the time you're done paying all the bills ... you have nothing left to pay for school fees or to even pay for the [transportation] loan.... The burden is on Mom, 'cause she's usually paying most of the bills now, so it's really tough on her, like really, really tough. (P5)

Those who were here without family support also reported economic challenges:

To be in [university] in Canada is very tough.... If you want to go to school, it's not something that everyone can do - it's really tough. Actually, I work 45 hours in the week [nights], plus 24 on the weekends. (P9)

This is reminiscent of reports by Wilkinson (2008). When students are both working and attending school, they may find it hard to progress academically; this places them at risk of dropping out. Dropping out of school isolates youth further and increases their vulnerability to recruitment in criminal activities (e.g., Ngo, 2010; Ngo et al., 2013). One youth (P12), who later became involved in drug-related crime, attributed leaving school to financial difficulties: "I feel like I can't afford to go to school and pay and still survive, so I feel like I had to work.” Another (P13) stated, "I was working two jobs and I was going to [high] school.... You gotta do what you gotta do." One participant (P7) stated that parents in her community did not want their children to be employed while attending school. However, this conflicted with their children's desire for popular items (e.g., brand name running shoes, iPods), and led some youth to find illegal ways to achieve their goals. She elaborated:

The trend right now is ... whatever the TV says is fine.... The problem is it's very expensive, so ... if you wanna be considered as somebody but you don't have the money, what do you do? You go steal from whoever you can.... And the kids that don't work ...? They start selling drugs.

This quote echoes reports from previous studies that the pressure to conform and to develop a sense of belonging can place youth at greater risk of criminal activity (Rossiter \& Rossiter, 2009), particularly as adolescents often have difficulty distinguishing between needs (adequate clothing) and wants (the "right" outfit and accessories). Another youth (P11) spoke about the desire of youth in her community for access to cash:

The father's never involved in the kid's activity, so the mother is just struggling and struggling, and the money is not enough ... and [the kids] want quick money.... Some other kids just say, “Oh, yeah, you know, I just made \$1,000 yesterday, you know, by [dealing drugs]. Oh, it’s cool!” and ... that’s what they do. They sell.

Drug use can intensify dissension within families. One youth reported that many immigrants from her country chewed khat, a stimulant drug that can cause mood swings and other effects. 
International Journal of Child, Youth and Family Studies (2015) 6(4.1): 746-770

She explained that some males in her community spent as much as $\$ 100$ each per evening on the drug, an expensive practice that often led to family conflict: "The family are just starving and they're spending the money sitting in the basement with other men” (P11).

Because of limited family incomes, many participants had lived in subsidized housing in the city, and two of the criminally involved youth had been homeless at one time. In some of the social housing complexes, youth reported being exposed to criminal activity on a daily basis:

If you have at least five kids, you should be working two or three jobs at the same time. The government, maybe they will help you find a government house. But where the house is gonna be, the location? ... This kid, before he goes to school, he's seeing this guy in the morning ... making drug deals....This is normal stuff; that's how they see it. So they go and they do it. And they grow up with that mentality. (P2)

The transient, high-crime nature of some of the low-income neighbourhoods in which many newcomers settle has been identified elsewhere (e.g., Kanu, 2008; Kazemipur \& Halli, 2000; Ngo, 2010). These dysfunctional neighbourhoods have been described as "zones of decay" for young immigrants (Rossiter \& Rossiter, 2009).

Drug dealers, however, use the lure of money, power, and a sense of belonging to recruit gang members (Chuang \& CISSA, 2009; Ngo, 2010; Rossiter \& Rossiter, 2009):

[Gangs] approach you, like persuade you, like the benefit of being in a gang and how much money you can make ... and they make it sound more like a family. So, they're there for you like you're there for them. (P12)

However, this youth had declined the invitation to join a gang, suspecting that it would be difficult to leave once he had joined. Another participant explained that one of his friends had exited a gang because, as he stated, "he's helping them, and then when it's time for them to help him, they don't want to" (P13). Several of the participants in this study were aware of gangs in their schools and neighbourhoods; two had had friends recruited; two had become acquainted with gang members during their incarceration; and another had tried to mentor and help youth exit gangs in the community. However, the interviewees all stated that they themselves had not been involved in gangs.

\section{Knowledge of Canadian Laws}

Some youth became involved in criminal activities as a result of peer influences, and their knowledge of Canadian laws and legal sanctions was reported to be very limited. This finding is convergent with that of Ngo et al. (2013). Five participants in the current study had received some information on Canadian laws at school or at a settlement orientation; informal sources of information included personal reading, the Internet, and television (although most crime programs are American). One youth (P6) reported learning from others in her community that domestic violence was illegal in Canada, unlike in her home country, and that she could call 911 if her father beat her or her mother. Eight participants (including all three criminally involved youth) reported that they were ignorant of Canadian laws or had learned about the 
International Journal of Child, Youth and Family Studies (2015) 6(4.1): 746-770

consequences of breaking some laws only as a result of their own or another's experience. The following is representative of their comments:

... you cannot hit a girl. Whether she's your girlfriend or wife, no, you cannot here. You can get arrested. I found out about that ... when [my friend] hit his girlfriend when she was pregnant, and she fainted or something and the cops have to come. That's when I found that was wrong. (P13)

Another explained, "I learned about Canadian laws when I started getting myself into trouble started getting arrested and going to courts and such" (P12). A third asserted that his crime of dishonesty was “... not that bad — I'm not hurting nobody. Like what's the worst that could happen?” (P14). Had he known that he would be facing jail time if caught, he said he would not have committed the crime. In the experience of this incarcerated youth, information on Canadian law was not widely available to newcomers:

People tell them about where to get welfare, how to get their Social Insurance Number, health card ... but nobody talks to them about the law. And I think personally, that's the single most important thing, you know, 'cause coming from [country], for example, you know, spouses fight.... Here, it's a crime, you can't beat up your wife, or your wife can't beat you.

One youth (P11) reported that although police came to her ethnocultural community to talk about the law, it was only to parents; she recommended that the information be shared with both parents and youth. Another interviewee recommended that information on Canadian laws be shared in schools, agencies, and ethnocultural communities, as a series of classes or workshops, not just one seminar “'cause some people don't learn stuff in one day, so it's gotta be step by step” (P13). One participant emphasized the importance of teaching not only Canadian laws but also the consequences of crime:

When I get out [of jail], I'm gonna go to the [ethnocultural] community and help the other kids there, right? If someone showed up and talked about their experience, like my experience from being in jail, that would help the other kids ... understand better, even if they didn't know the language yet. They would know that, hey, we came to Canada, and this is what can happen here, you know?... Like in [home country], who cares if you're drunk and you're driving? No one. (P14)

Legislative reforms also need to be clearly communicated to all newcomers in a language in which they are proficient. With amendments to Canada's criminal code, new criminal offences have been introduced and increased mandatory minimum sentences imposed. A criminal record can result in the deportation of permanent residents under Canadian federal government law (Immigration and Refugee Protection Act, 2002, s. 36.1). The consequences of criminal convictions can be long-term, as explained by one participant:

I have like a criminal record, so most of the time ... as soon as the employer's aware of that, they're more scared to hire you and, at the same time, you have no other choices, so you keep looking mostly. (P12) 
International Journal of Child, Youth and Family Studies (2015) 6(4.1): 746-770

These circumstances could also tempt some youth to become involved in more lucrative criminal activity, as noted by, for example, Ngo et al.(2013) and Wortley (2003). One youth (P11) stated that, in some cases within her community, "as soon as [parents] find out the kid has been doing something really bad and maybe he has hurt somebody or committed an assault, they'll ship [him] back home [before he can be arrested].” The lack of knowledge of Canadian laws and legal sanctions reported by participants in this study shows the critical importance of ensuring that this information is communicated effectively to both newcomer youth and their families (congruent with Wortley, 2003).

\section{Support Networks}

Most participants in this study reported that they had received very limited psychosocial support when they first arrived in Canada. One youth (P11) stated that it would be very helpful to have buddies or mentors in schools who would listen to newcomer youth, provide advice, and not judge them if they were experiencing difficulties. Those who had immigrated alone or whose parents were working two or more jobs were disadvantaged, as one youth (P12) explained: “There's no one who's there to guide you - like here, this is good, this is bad....” Participants reported a lack of positive role models, especially for young males, similar to findings from earlier studies (e.g., Anisef et al., 2003; Rossiter \& Rossiter, 2009; Seat, 2003) reflecting reports of children being raised by television and limited supervision leaving some youth vulnerable to negative influences in their communities.

Positive relationships with family served to lessen the impact of negative influences in participants’ lives. One participant credited his family for keeping him in school:

My relatives ... they was pushing me every day, saying, "We didn’t have chance to go to school, and now we have a chance, so we need you to be successful, we need you to get education, to get a degree”. (P10)

ESL teachers and programs were also praised for the support that they provided to youth:

My first [ESL] teacher ... she was wonderful, like she guided me a lot and told me a lot of stuff and advised me, and even so right now every time she sees me, she asks me how's everything, what you can do, who you can talk to. (P7)

Individuals such as these can play nurturing and sustaining roles in the lives of newcomer youth.

Some schools also offered valuable extracurricular opportunities, such as leadership programs, that attracted newcomer youth:

... we would go volunteer at different places, we would volunteer at different events at the school, so it builds up really our self-confidence and how we would interact with people and I think it kind of like built up our public speaking skill because we would participate in the meetings every Monday. And it was a really, really, really positive student body. (P3)

Associating with youth from other cultural backgrounds was seen as an advantage by several interviewees; as one youth (P2) explained, "I went to [name] high school where I think I was the 
International Journal of Child, Youth and Family Studies (2015) 6(4.1): 746-770

only student from [country]. I think it was a good thing because I was able to make friends with people from other cultures, as well.” Those youth who made an effort to develop a network of friends outside of their ethnocultural group found that this was beneficial to them:

The first year, it was just very hard to open up to a lot of different backgrounds of students.... I stick to my [ethnocultural] friends.... It was just pretty much our own circle ... but I realized after ... a year and a half that I really need to expand ... my horizon of friends and because I think that by doing that, there's a lot more opportunities that I can make. (P3)

The social networks and skills developed in school settings had positive effects on participants' development, supporting findings by Anderman (2002) and Dei (2007).

Another support that was perceived as important for most participants in both groups was their faith, which helped to create a sense of belonging and stability for youth and their families. As one youth (P1) explained, "Church did a lot for us, especially for my family. It's a big thing in our family and so to find that, it was like we had a community — somewhere to belong." This sense of belonging satisfied a basic need for many (Baumeister \& Leary, 1995; Maslow, 1970).

Community groups and organizations such as Catholic Social Services, the Mennonite Centre for Newcomers, and others also provided new possibilities. One participant stated:

[A settlement service representative] really opened the doors to the opportunities that are available in Canada.... It's just a matter of knowing about them and knowing how to take advantage of them.... It was a really nice turning point in our lives and from there on, things have gone a lot better for us. (P8)

It is clear from the statement above that one caring individual can have a significant impact on the future prospects of immigrant youth. School teachers, programs, and community groups were all reported to support newcomer youth and give them a sense of belonging in the wider community.

\section{Educational Experiences}

Congruent with previous research (e.g., Anisef et al., 2003; Kanu, 2008; Ngo \& Schleifer, 2005), school placement issues were a source of frustration and discontent for many immigrant students and their parents. One participant explained:

Here in Canada it's based on your age; you're put [in a grade] according to your age, but from where we come from it's based on your knowledge. You write a test and they put you in a grade that's suitable for you. So I was put back three years behind and I had to repeat junior high all over again. So that was very frustrating. (P2)

Some teachers were perceived to have neither the time nor the skills to adapt subject content to accommodate ESL learners (as noted also by Kanu, 2008), and additional supports were not always available for either the English language learners or their teachers: 
International Journal of Child, Youth and Family Studies (2015) 6(4.1): 746-770

Teachers have so much on their hands....They kind of deliver their curriculum and their plan.... Anything else that a student might need - extra help with homework for me because of my language - was not there. The teacher didn't have the language [teaching] skills or the time to help me. (P8)

Without the necessary assistance, youth often made slower academic progress. One youth (P11) stated, "It would be great if in our ... communities, we had some sort of after-school homework, or some tutoring for the kids....” Another recommended that the age cap for attending high school be raised (a recommendation supported by Garnett, 2010) so that students had a chance to complete high school with their peers. Those who take upgrading courses after leaving high school must pay tuition fees that many immigrants cannot afford.

Parents were often unable to provide educational support or advocacy, as many had little or no understanding of the Canadian school system and limited contact with teachers. One participant explained:

My parents ... were so intimidated to go into the classrooms and to talk to the teachers because they felt like, the fact that they didn't speak English, or the fact that they didn't know about the school system, the teacher would automatically think of them as not very smart people and that would kind of create that stereotype of me not being very smart. (P8)

However, with the support of their families, nine of the eleven youth leaders and one of the three criminally involved youth aspired to or were attending post-secondary programs. One youth (P8) explained her motivation this way: "I want to change lives, make meaningful changes to the world, and I think that a law degree can be a useful weapon, a positive weapon to do that." These findings echo the aspirations of participants in earlier studies by Seat (2003), and Krahn and Taylor (2005).

\section{Racism and Discrimination}

When asked if they had experienced racism or discrimination since their arrival in Canada, the majority of participants responded affirmatively. Some youth_also reported numerous incidents of discrimination at work, in the local community, and at school. One female youth stated, “A boy in my ... classroom ... followed me to the washroom and began yelling at me, telling me to go back to my country" (P8). Another youth who had experienced everyday bullying and discrimination in Canadian schools explained, "People here just call each other names, but there's no fist fights, there's no slapping, there's no hair pulling, none of that here" (P11). She attributed her attitude to resilience developed in schools in her home country, where “there's bullying, there's fights every day, in class, at class, everything. So you had to be really tough ... and you have to portray this image of fear into the other kids so they wouldn't fight you.”

Discrimination in Canadian schools was also attributed to inter-tribal conflicts among youth. The same interviewee reported that African children were often told by their parents not to associate with youth from different tribes. She maintained that some children, who may not have experienced violence back home, were being taught to hate in Canada. Conflict with youth 
International Journal of Child, Youth and Family Studies (2015) 6(4.1): 746-770

from other tribes and minority groups, as well as those from mainstream Canadian society, constituted a serious issue for many newcomer adolescents. As work by Berry and colleagues (2006) has shown, discrimination has a negative effect on psychological adaptation (personal well-being, mental health) and on sociocultural adaptation (interactional competence in a new culture).

\section{Cultural Identity}

Developing a pluricultural identity was a challenge that had social and academic consequences for most youth, as explained by this participant:

You tend to struggle between two cultures. The cultures you have at home where it's very close-knit — it's very different from what you're used to outside, right?... [Newcomer youth] don't really know how to balance the two cultures. (P8)

Another youth (P11) explained that, unlike many of her Muslim friends who would leave home wearing a religious head covering and then change at school, she had refused to wear a headscarf as an adolescent. As a result of continuing conflict with her parents and in particular with her father, who was very strict, she dropped out of high school, left home, and eventually completed her education in adult upgrading classes. Difficulties with cultural adaptation and intergenerational conflict have been noted by Anisef et al. (2003), Ngo (2010), Ngo et al.(2013), and Rossiter and Rossiter (2009), among others; these stories highlight some of the struggles that families face in parenting their children in a society with differing norms.

\section{Involvement in Community Programs}

Community-based organizations offer a variety of programs and mentorship opportunities to engage young newcomers; however, many have difficulty connecting with immigrant youth in the wider community. All but one participant in the present study were involved in their ethnocultural organizations or their churches. Unlike the three criminally involved youth, however, 10 of the other 11 youth were involved in multiple activities in the larger community, eight of them extensively.

Participants explained the importance, particularly early in the settlement process, of programs available to them through community organizations and settlement agencies.

I was very involved in [settlement agency]. They will teach about the Canadian culture, so how the police work, you know, rules and stuff, and my [parent] and I will always go there.... They have a summer program where they show you around the city.... They also gave us something like a sponsor family, so we had like a family that helped us out around the city. (P1)

Citizenship and Immigration Canada's Cultural Links program (formerly the Host Program) is designed to facilitate settlement by matching newcomers with trained volunteers whose role is to welcome and engage newcomers. Several models of similar promising programs have been offered in various parts of the country to facilitate the integration of individuals or groups of immigrant youth into Canadian society; however, the majority of them have been subject to only informal, in-house evaluations (Anisef et al., 2005), funding is limited, and there are often long 
International Journal of Child, Youth and Family Studies (2015) 6(4.1): 746-770

waiting lists for newcomers to be matched with volunteers from the wider community (Derwing \& Waugh, 2012).

The majority of youth leaders were involved in newcomer or youth programs offered by organizations such as Air Cadets, Boys and Girls Clubs/Big Brothers Big Sisters, the Canadian Council for Refugees, Catholic Social Services, faith communities, the John Humphrey Centre for Peace and Human Rights, the Mennonite Centre for Newcomers, Multicultural Health Brokers, music groups, community recreational programs, and others. Programs such as these empower youth, develop leadership skills, and provide valuable role models for others in the immigrant community (Ngo et al., 2013). For example, one interviewee reported:

This summer I was helping with Boys and Girls Club. They had a program where they ... help junior high kids. They have difficulties with the culture and stuff. And they all do activities for them. So, kind of like a mentorship program.... I would have loved to have somebody like that.... It would have helped me more, I think. (P1)

The significance of mentorship was echoed by other participants in the study. When asked what wisdom they would like to share with newcomer youth, one participant advised:

... find really positive role models, you know? Because it's really easy to fall off track and lead your life in a disastrous way, but if you have the right people that will show you around, it will help you — it's very good. (P2)

This was reiterated by another (P14), who warned that immigrants are often given misinformation to lure them into the drug trade or black market ("selling drugs, oh, it's okay"). He advised newcomer youth to "stay close to family and actually true friends ... or talk to somebody else who is like older ... or has been here.”

Several participants explained the importance of giving back to Canadian society. One youth (P10) stated, “Once I help people, I feel good about myself, like helping people to be successful.” Another offered this opinion:

Main thing is, immigrants should have open minds, too, you know, because it's a give and take. You move to a country, you have to have an open mind to that country. You have to see that country as your new home or that environment as your new home, and give to the environment, because you'll never take out if you don’t give. (P4)

Participation in prosocial group activities that allowed them to contribute and grow was reported to increase the self-esteem and sense of belonging of participants in this study. It has also been reported to promote newcomer youths’ resilience and adaptation (Este \& Ngo, 2011).

Youths' perceptions of the benefits of volunteerism, echoing those of stakeholders in Ngo et al. (2013), constitute a key contribution of this study. Recognizing the lack of role models for newcomers, they were providing mentorship for younger immigrants and found it rewarding. Interestingly, the three criminally involved youth in this study did not report extensive involvement in the wider community; their activities were restricted to their ethnocultural organizations and their churches. Mentorship and involvement in the larger community, however, appeared to be important for successful integration. 
International Journal of Child, Youth and Family Studies (2015) 6(4.1): 746-770

\section{Conclusion}

Analyses of participant interview transcripts revealed that the settlement and adaptation of the immigrant and refugee youth in this study were influenced by negative pre-migration experiences (e.g., trauma resulting from war and violence); difficult socioeconomic circumstances (e.g., poverty, unsafe neighbourhoods); lack of knowledge of Canadian laws and legal sanctions; challenging educational experiences (e.g., limited support from mainstream teachers, little or no parental engagement with the school); racism and discrimination; and cultural identity issues. However, several factors were reported to mitigate the negative influences in participants' lives. These included, in particular, support networks (e.g., in ESL programs, faith communities, settlement agencies) and involvement in cultural and recreational community programs as participants and leaders.

The contributions of the participants whose voices have been included here confirm many of the factors affecting the settlement of immigrant youth that have been identified in previous studies (e.g., Anisef et al., 2003; Ngo \& Schleifer, 2005; Rossiter \& Rossiter, 2009). They also highlight, in youths' own words, aspects of their experiences that have not been closely examined elsewhere: the negative impacts of refugee transportation loans and of subsidized housing environments; their lack of knowledge of Canadian laws and sanctions; and the benefits of volunteering in community activities and mentorship programs.

The findings of this qualitative study must be interpreted in light of several limitations, one of which is the small sample size: interviews were conducted with 14 youth. The participants were not necessarily representative of the numbers or proportions in local immigrant communities. Future studies of larger groups could explore differences in male and female responses and in youths' understanding of gender script in their home countries and in Canada. Although some of the youth interviewed were able to communicate their ideas more articulately than others, the interviews were all instructive and contributed to a greater understanding of the settlement experiences of vulnerable immigrant and refugee youth; in particular, they highlighted the value of mentors, community organizations, and knowledge of Canadian laws.

A number of key recommendations follow, based on shared experiences of the participants in this study. The first addresses education: schools are the most accessible context in which to address many of the issues facing newcomer youth. To foster academic success, transition programming should be provided for immigrant youth and their families to address procedural, social, and academic aspects of the education system. Adequate supports and accommodations should be provided in the schools to help youth integrate successfully. Pre-service and in-service teachers need to understand students' pre- and post-migration backgrounds and develop the skills to adapt instruction to effectively accommodate English language learners.

Second, we recommend the development, formal external evaluation, and enrichment of programs that promote mentoring, volunteerism, leadership skills, a sense of belonging, and the integration of immigrant youth into the wider community. Interviews revealed that participation in prosocial activities was a key support in the lives of the youth in this study. There is a clear need for more mentoring and more Community Connections programs to facilitate successful adaptation and integration; to expand relationship networks for both youth and, by extension, their families; and to provide additional support for independent youth. Within the school 
context, designated peer buddy or mentoring programs could be provided for those learning the English language both at the beginning of and throughout the school year. Ethnocultural organizations should work closely with settlement agencies, local government, and community groups to ensure that affordable out-of-school recreational programs, both sports and art-based, are available in schools and neighbourhoods and have the necessary supports (e.g., transportation, fee waivers). More efficient means should also be used to make newcomer families aware of these and other accessible programs available in their communities (e.g., free library cards, subsidized recreation for newcomer and low-income families). This information needs to be available in schools, registry offices, city offices, libraries, recreational centres, settlement agencies, clinics, and other frequently accessed locations, as well as in the media (local ethnic radio, community newspapers). Accessible cultural and recreational programs in schools and neighbourhoods should be available not only to engage youth participants but also to provide leadership training and experience for immigrants from diverse cultures. These and other opportunities to become involved in community activities in various capacities need to be more actively and effectively communicated to youth and their families.

Finally, we encourage the development of culturally sensitive programs to introduce immigrant youth and their families to the Canadian justice system. The financial and psychological pressures of poverty make some youth vulnerable to involvement in criminal activities. Those participants who had come into conflict with the law expressed their lack of understanding of Canadian laws and sanctions, which differ significantly from laws in their home countries. Authoritative, up-to-date information on Canadian laws and legal sanctions for youth, families, and immigrant-serving agencies is vital to the well-being of the newcomer community. Without this knowledge, immigrants face the risk of fines, incarceration, or possibly deportation, at significant cost to themselves, their communities, and Canadian society.

More federal funding is required to achieve these goals. Although the federal government makes immigration decisions, many of the subsequent costs are downloaded to the provinces and municipalities in which newcomers settle. The mandatory long-form Canadian census was replaced by a voluntary National Household Survey in 2010; many analysts believe that vulnerable groups, such as recent immigrants, could be under-represented as a result of this change (Reitz, 2014, p. 112). Further responsibility is therefore placed on both researchers and advocates to identify and communicate the needs of newcomers.

Greater educational support, awareness of and access to opportunities for community involvement, and knowledge of Canadian systems will inform and guide newcomer youth through their settlement and adaptation process, help them to develop a sense of belonging, and facilitate fuller participation in Canadian society. Combining these with systemic changes on the part of the receiving community, such as the elimination of refugee transportation loans; recognition of foreign credentials; adequate funding for settlement services; cultural sensitivity programs in schools, workplaces, and the wider community (e.g., Rossiter \& Rossiter, 2009); employment equity and unionization of the workforce (Galabuzi, 2006); provision of a guaranteed minimum income for all; and education of the general public regarding the benefits of immigration, will help to promote inclusion and social cohesion. 
International Journal of Child, Youth and Family Studies (2015) 6(4.1): 746-770

\section{References}

Adler, S. (1977). Maslow's need hierarchy and the adjustment of immigrants. International Migration Review, 11(4), 444-451. http://dx.doi.org/10.2307/2545398

Anderman, E. M. (2002). School effects on psychological outcomes during adolescence. Journal of Educational Psychology, 94(4), 795-809. http://dx.doi.org/10.1037/0022-0663.94.4.795

Anisef, P., Brown, R. S., Phythian, K., Sweet, R., \& Walters, D. (2008). Early school leaving among immigrants in Toronto secondary schools (CERIS Working Paper No. 67). Toronto, ON: Joint Centre of Excellence for Research on Immigration and Settlement.

Anisef, P., Kilbride, K. M., \& Khattar, R. (2003). The needs of newcomer youth and emerging "best practices" to meet those needs. In P. Anisef \& K. M. Kilbride (Eds.), Managing two worlds: The experiences and concerns of immigrant youth in Ontario (pp. 196-234). Toronto, ON: Canadian Scholars’ Press.

Anisef, P., Poteet, M., Anisef, D., Farr, G., Poirier, A., \& Wang, H. (2005). Issues confronting newcomer youth in Canada: Alternative models for a national youth host program (CERIS Working Paper No. 39). Toronto, ON: Joint Centre of Excellence for Research on Immigration and Settlement.

Baumeister, R. F., \& Leary, M. R. (1995). The need to belong: Desire for interpersonal attachments as a fundamental human motivation. Psychological Bulletin, 117(3), 497-529. http://dx.doi.org/10.1037/0033-2909.117.3.497

Berger, R. (2008). Fostering post-traumatic growth in adolescent immigrants. In L. Liebenberg \& M. Ungar (Eds.), Resilience in action: Working with youth across cultures and contexts (pp. 87-100). Toronto, ON: University of Toronto Press.

Berry, J. W. (2008). Acculturation and adaptation of immigrant youth. Canadian Diversity, 6(2), 50-53.

Berry, J. W., Phinney, J. S., Sam, D. L., \& Vedder, P. (2006). Immigrant youth in cultural transition: Acculturation, identity, and adaptation across national contexts. Mahwah, NJ: Lawrence Erlbaum.

Block, S. \& Galabuzi, G.-E. (2011). Canada's colour coded labour market: The gap for racialized workers. Ottawa, ON: The Canadian Centre for Policy Alternatives. Retrieved from https://www.policyalternatives.ca/publications/reports/canadas-colour-codedlabour-market

Campaign 2000. (2012). Needed: A federal action plan to eradicate child and family poverty in Canada. Toronto, ON: Family Service Toronto.

Canadian Council for Refugees. (n.d.). Refugee transportation loans. Retrieved from http://ccrweb.ca/en/transportation-loans 
International Journal of Child, Youth and Family Studies (2015) 6(4.1): 746-770

Canadian Council on Social Development. (2006). The progress of Canada's children and youth. Kanata, ON: Author. Retrieved from http://www.ccsd.ca/resources/ProgressChildrenYouth/pdf/pccy_portrait.pdf

Chuang, S. S., \& Canadian Immigrant Settlement Sector Alliance (CISSA). (2009). New start: Immigrant serving agencies' perspective on the issues and needs of immigrant and refugee children and youth in Canada. Ottawa, ON: Citizenship and Immigration Canada.

Chuang, S. S., \& Canadian Immigrant Settlement Sector Alliance (CISSA). (2010). New start for youth study: An examination of the settlement pathways of newcomer youth. Ottawa, ON: Citizenship and Immigration Canada.

Citizenship and Immigration Canada. (2012). Facts and figures 2012 - Immigration overview: Permanent and temporary residents. Ottawa, ON: Author.

Cummins, J. (2000). Language, power and pedagogy: Bilingual children in the crossfire. Toronto, ON: Multilingual Matters.

Dei, G. J. S. (2007). Schooling as community: Race, schooling, and the education of African youth. Journal of Black Studies, 38(3), 346-366. http://dx.doi.org/10.1177/0021934707306570

Denzin, N. K., \& Lincoln, Y. S. (2003). Collecting and interpreting qualitative materials (2nd ed.). Thousand Oaks, CA: Sage.

Derwing, T. M., DeCorby, E., Ichikawa, J., \& Jamieson, K. (1999). Some factors that affect the success of ESL high school students. The Canadian Modern Language Review, 55(4), 532-547. http://dx.doi.org/10.3138/cmlr.55.4.532

Derwing, T. M., \& Waugh, E. (2012). Language skills and the social integration of Canada's adult immigrants. (IRPP Study 31). Montreal, PQ: Institute for Research on Public Policy.

Dudley, L. (2007). Integrating volunteering into the adult immigrant second language experience. The Canadian Modern Language Review, 63(4), 539-561. http://dx.doi.org/10.3138/cmlr.63.4.539

Ellis, B. H., MacDonald, H. Z., Lincoln, A. K., \& Cabral, H. J. (2008). Mental health of Somali adolescent refugees: The role of trauma, stress, and perceived discrimination. Journal of Consulting and Clinical Psychology, 76(2), 184-193. http://dx.doi.org/10.1037/0022-006x.76.2.184

Este, D., \& Ngo, H. V. (2011). A resilience framework to examine immigrant and refugee children and youth in Canada. In S. S. Chuang \& R. P. Moreno (Eds.), Immigrant children: Change, adaptation, and cultural transformation (pp. 27-50). Plymouth, UK: Lexington Books.

Ferrer, A. M., Picot, G., \& Riddell, W. C. (2014). New directions in immigration policy: Canada's evolving approach to the selection of economic immigrants. International Migration Review, 48(3), 846-867 http://dx.doi.org/10.1111/imre.12121 
International Journal of Child, Youth and Family Studies (2015) 6(4.1): 746-770

Frank, K., Phythian, K., Walters, D., \& Anisef, P. (2013). Understanding the economic integration of immigrants: A wage decomposition of the earnings disparities between native-born Canadians and recent immigrant cohorts. Social Sciences, 2(2), 40-61. http://dx.doi.org/10.3390/socsci2020040

Galabuzi, G.-E. (2006). Canada's economic apartheid: The social exclusion of racialized groups in the new century. Toronto, ON: Canadian Scholars' Press.

Garnett, B. (2010). Toward understanding the academic trajectories of ESL youth. The Canadian Modern Language Review, 66(5), 677-710. http://dx.doi.org/10.3138/cmlr.66.5.677

Howard Research \& Management Consulting. (2006). Review of ESL K-12 program implementation in Alberta: Final report. Edmonton, AB: Alberta Education.

Immigration and Refugee Protection Act. (2002, S.C. 2001, c. 27, s. 36.1). Retrieved from http://laws.justice.gc.ca/PDF/I-2.5.pdf

Kanu, Y. (2008). Educational needs and barriers for African refugee students in Manitoba. Canadian Journal of Education, 31(4), 915-940.

Kanu, Y. (2009). Educational pathways to successful social integration for African refugee students in Manitoba. Our Diverse Cities (6), 114-119.

Kazemipur, A., \& Halli, S. (2000). The invisible barrier: Neighbourhood poverty and integration of immigrants in Canada. Journal of International Migration and Integration, 1(1), 85100. http://dx.doi.org/10.1007/s12134-000-1009-1

Kia-Keating, M., \& Ellis, B. H. (2007). Belonging and connection to school in resettlement: Young refugees, school belonging, and psychosocial adjustment. Clinical Child Psychology and Psychiatry, 12(1), 29-43. http://dx.doi.org/10.1177/1359104507071052

Kilbride, K. M., \& Anisef, P. (2001). To build on hope: Overcoming the challenges facing newcomer youth at risk in Ontario. Toronto, ON: Joint Centre of Excellence for Research on Immigration and Settlement.

Krahn, H., \& Taylor, A. (2005). Resilient teenagers: Explaining the high educational aspirations of visible-minority youth in Canada. Journal of International Migration and Integration, 6(3-4), 405-434. http://dx.doi.org/10.1007/s12134-005-1020-7

LaBoucane-Benson, P., Hossack, F., Erickson, K., \& Grunland, M. (2009). Soccer moms are part of the solution: A cost-benefits analysis of community-based gang crime prevention. Ottawa, ON: Public Safety Canada.

Lamba, N. K., \& Krahn, H. (2003). Social capital and refugee resettlement: The social networks of refugees in Canada. Journal of International Migration and Integration, 4(3), 335-360. http://dx.doi.org/10.1007/s12134-003-1025-z

Lauer, S., Wilkinson, L., Yan, M. C., Sin, R., \& Tsang, A. K. T. (2012). Immigrant youth and employment: Lessons learned from the analysis of LSIC and 82 lived stories (RDC Research Paper No. 29). Hamilton, ON: Statistics Canada Research Data Centre, McMaster University. 
International Journal of Child, Youth and Family Studies (2015) 6(4.1): 746-770

Li , J. (2010). 'My home and my school': Examining immigrant adolescent narratives from the critical sociocultural perspective. Race Ethnicity and Education, 13(1), 119-137. http://dx.doi.org/10.1080/13613320903550154

Lustig, S. L., Kia-Keating, M., Knight, W. G., Geltman, P., Ellis, H., Kinzie, J. D., ... Saxe, G. N. (2004). Review of child and adolescent refugee mental health. Journal of the American Academy of Child and Adolescent Psychiatry, 43(1), 24-36. http://dx.doi.org/10.1097/00004583-200401000-00012

Magro, K. (2009). Building bridges to social inclusion: Researching the experiences and challenges of the Lost Boys and Girls of Sudan community in Winnipeg (Working Paper No. WP01-09). Edmonton, AB: The Prairie Metropolis Centre.

Maslow, A. B. (1970). Motivation and personality. New York: Harper and Row.

McBrien, J. L. (2005). Educational needs and barriers for refugee students in the United States: A review of the literature. Review of Educational Research, 75(3), 329-364. http://dx.doi.org/10.3102/00346543075003329

Montgomery, E. (2010). Trauma and resilience in young refugees: A 9-year follow-up study. Development and Psychopathology, 22, 477-489. http://dx.doi.org/10.1017/s0954579410000180

Ngo, H. V. (2010). Unravelling identities and belonging: Criminal gang involvement of youth from immigrant families (Unpublished doctoral dissertation). University of Calgary, Calgary, AB.

Ngo, H. V., Rossiter, M. J., \& Stewart, C. (2013). Understanding risk and protective factors associated with criminal involvement in a multicultural society. International Journal of Child, Youth and Family Studies, 4(1), 54-71.

Ngo, H. V., \& Schleifer, B. (2005). Immigrant children and youth in focus. Canadian Issues, Spring, 29-33.

Nguyen, S. D. (1987). Maslow's hierarchy of needs and refugee resettlement. In K. B. Chan \& D. M. Indra (Eds.), Uprooting, loss and adaptation: The resettlement of Indochinese refugees in Canada (pp. 444-451). Ottawa, ON: Canadian Public Health Association.

O’Hara, S., \& Pritchard, R. H. (2008). Meeting the challenge of diversity: Professional development for teacher educators. Teacher Education Quarterly, 35(1), 43-61.

Onchwari, G., Onchwari, J. A., \& Keengwe, J. (2008). Teaching the immigrant child: Application of child development theories. Early Childhood Education Journal, 36, 267273. http://dx.doi.org/10.1007/s10643-008-0269-9

Oxman-Martinez, J., Rummens, A. J., Moreau, J., Choi, Y. R., Beiser, M., Ogilvie, L., \& Armstrong, R. (2012). Perceived ethnic discrimination and social exclusion: Newcomer immigrant children in Canada. American Journal of Orthopsychiatry, 82, 376-388 http://dx.doi.org/10.1111/j.1939-0025.2012.01161.x

Picot, G., Lu, Y., \& Hou, F. (2009). Immigrant low-income rates: The role of market income and government transfers. Perspectives on Labour and Income, 10(12), 13-27. 
International Journal of Child, Youth and Family Studies (2015) 6(4.1): 746-770

Reitz, J, G. (2014). Canada: New initiatives and approaches to immigration and nation building. In J. F. Hollifield, P. L. Martin, \& P. M. Orrenius (Eds.), Controlling immigration: A global perspective (3rd ed., pp. 88-116). Stanford, CA: Stanford University Press.

Rossiter, M. J., \& Rossiter, K. R. (2009). Diamonds in the rough: Bridging gaps in supports for at-risk immigrant and refugee youth. Journal of International Migration and Integration, 10 (4), 409-429. doi:10.1007/s12134-009-0110-3

Rothe, E. M., Pumariega, A. J., \& Sabagh, D. (2011). Identity and acculturation in immigrant and second generation adolescents. Adolescent Psychiatry, 1, 72-81. http://dx.doi.org/10.2174/2210676611101010072

Seat, R. (2003). Factors atfecting the settlement and adaptation process of Canadian adolescent newcomers sixteen to nineteen years of age. In P. Anisef \& K. M. Kilbride (Eds.), Managing two worlds: The experiences and concerns of immigrant youth in Ontario (pp. 162-195). Toronto, ON: Canadian Scholars’ Press.

Shakya, Y. B., Khanlou, N., \& Gonsalves, T. (2010). Determinants of mental health for newcomer youth: Policy and service implications. Canadian Issues, Summer, 98-102.

Shields, J., Kelly, P., Park, S., Prier, N., \& Fang, T. (2011). Profiling immigrant poverty in Canada: A 2006 census statistical portrait. Canadian Review of Social Policy, 65/66, 92111.

Statistics Canada. (2011). Immigration and ethnic diversity in Canada. Ottawa, ON: Statistics Canada. Retrieved from http://www12.statcan.gc.ca/nhs-enm/2011/as-sa/99-010-x/99-010x2011001-eng.cfm

Toohey, K., \& Derwing, T. M. (2008). Hidden losses: How demographics can encourage incorrect assumptions about ESL high school students' success. The Alberta Journal of Educational Research, 54(2), 178-193.

Ungar, M. (2012). Social ecologies and their contribution to resilience. In M. Ungar (Ed.), The social ecology of resilience: A handbook of theory and practice (pp. 13-31). New York, NY: Springer Science+Business Media. http://dx.doi.org/10.1007/978-1-4614-0586-3_2

Watt, D., \& Roessingh, H. (1994). ESL dropout: The myth of educational equity. The Alberta Journal of Educational Research, 40(3), 283-296.

Wideman-Johnston, T. (2014). Immigrant students’ health. In C. A. Brewer \& M. McCabe (Eds.), Immigrant and refugee students in Canada (pp. 20-30). Edmonton, AB: Brush Education.

Wilkinson, L. (2002). Factors influencing the academic success of refugee youth in Canada. Journal of Youth Studies, 5(2), 173-193. http://dx.doi.org/10.1080/13676260220134430

Wilkinson, L. (2008). Labor market transitions of immigrant-born, refugee-born, and Canadianborn youth. Canadian Review of Sociology, 45(2), 151-76.

http://dx.doi.org/10.1111/j.1755-618x.2008.00008.x 
International Journal of Child, Youth and Family Studies (2015) 6(4.1): 746-770

Wilson, R. M., Murtaza, R., \& Shakya, Y. B. (2010). Pre-migration and post-migration determinants of mental health for newly arrived refugees in Toronto. Canadian Issues, Summer, 45-49.

Wortley, S. (2003). Hidden intersections: Research on race, crime, and criminal justice in Canada. Canadian Ethnic Studies Journal, 35(3), 99-117. 